Systematic Review

\title{
The Analysis of the Influencing Factors related to the Effectiveness of Discharge Planning Implementation in Hospitals: A Systematic Review
}

\author{
Hari Soebagiyo, Kornelis Nama Beni and Tan Nina Fibriola \\ Faculty of Nursing, Universitas Airlangga, Surabaya, East Java, Indonesia
}

\begin{abstract}
Introduction: Discharge Planning is one of the agendas that is a part of nursing duties. This is not only complicated but it is also a long-term activity, starting from when the patients are admitted to hospital until they are allowed to go home. Factually, it cannot be denied that effective nursing discharge planning implementation will provide benefits for the patient, their family and the professionals within the health care setting. Based on those facts, the author composed this systematic review with the purpose of identifying the influential factors that have a role in terms of the effectiveness of nursing discharge planning implementation in hospitals
\end{abstract}

Methods: The researcher conducted their investigation in February 2019 and this involved the exploration of scientific papers from ProQuest and Scopus using the keywords 'nursing discharge planning', 'effectiveness' and 'implementation'. This paper identified 15 relevant research articles from 500 original full texts. These papers were analyzed according to the inclusion criteria and the impeding factors in discharge planning implementation. It involved 1 quasi-RCT and 14 descriptive research studies.

Results: As a result, from the 10.000 respondents, it was found that the enhancing factors include effective communication at $43 \%$ and the factors causing impedance in nursing discharge planning effectiveness includes the continuity of staff at $38 \%$.

Conclusion: The dominant factor of impedance as stated in the interview sessions was a lack of time to do the nursing discharge planning properly.

\section{ARTICLE HISTORY}

Received: December 26, 2019

Accepted: December 31, 2019

\section{KEYWORDS}

Discharge planning; family; hospital; influence factor, effectiveness

\section{CONTACT}

Hari Soebagiyo

$\triangle$ hari.soebagiyo-

2018@fkp.unair.ac.id

$\equiv$ Faculty of Nursing, Universitas

Airlangga, Surabaya, Indonesia

Cite this as: Soebagiyo, H., Beni, K. N. \& Fibriola, T. N. (2019). The Analysis of the Influencing Factors related to the Effectiveness of Discharge Planning Implementation in Hospitals: A Systematic Review. Jurnal Ners, 14(3si), 217-220. doi:http://dx.doi.org/10.20473/jn.v14i3(si).17103

\section{INTRODUCTION}

Discharge planning is considered to be an important part of the current health services. This form of planning is a systematic planning process starting from when the patient is admitted to hospital. Discharge planning must be focused on the patient's problem, which includes prevention, rehabilitative and nursing care that provides the patients and their families with an understanding of the disease and any caring interventions that must be done at home, in addition to explaining the patient's needs and ensuring that they have the references needed for further treatment.

The phenomena today of discharge planning for patients is not optimal, where nurses just do a limited form of the implementation of routine activities in the form of the information on re-control. The nonoptimal implementation of discharge planning can be caused by the effectiveness of the process of carrying out this activity. Effectiveness is a condition where a job can be done on time and in accordance with the plan that has been set (Indonesian dictionary). With effective discharge planning, this can be achieved by a decreased length of stay, decreased readmission and decreased mortality. Starting from the points above, the author wanted to explore the factors that may enhance and impede discharge planning implementation. 


\section{MATERIALS AND METHODS}

The method used in the preparation of this systematic review began with the selection of interesting and specific topics. We chose the topic of discharge planning, which is one of the problems in nursing management that has not been resolved up until now. After selecting a topic, we conducted a systematic review and determined the keywords. The keywords used were 'nursing discharge planning', 'influencing factors', 'effectiveness' and 'implementation'.

A journal search was carried out focused on trusted publishers such as SCOPUS and Pro-Quest with the yearly restriction being between 2004 - 2018 in the nursing management area. From the 500 articles that were obtained, 15 articles were selected that were in accordance with the established inclusion criteria that examined the enhancing and impending factors in the effectiveness of discharge planning implementation.

\section{RESULTS}

Based on the results of a review 15 articles collected. The discussion about the factors that can enhance and impend the implementation of discharge planning effectiveness are as follows

\section{Level of knowledge}

The level of knowledge of a nurse is an important factor in achieving the effectiveness of discharge planning. In his research has proved that for nurses who have been trained in the method and concept of discharge planning will be more effective in implementing discharge planning than nurses who have not trained (Abdulrdha \& Mansour, 2018).

\section{Patients readiness for discharge}

Patient readiness to do discharge planning, also an important factor in achieving discharge planning effectiveness with its predictors are: sex, age, education status, marital status will be very helpful in achieving discharge planning, especially when at home (Kaya \& SainGuven, 2018).

\section{Discharge planning that has applicability capabilities}

Carrie HK et al (2012) states that; the ability of the discharge planning format to be implemented is very influential for effective discharge planning. Furthermore in the discussion of the participants from his research also stated that the lack of a number of human resources, skills, and time also greatly affected the implementation of discharge planning effectively (Wong et al., 2011).

Lack of planning of discharge programs and lack of coordination of health workers with different scientific disciplines

Lack of coordination between health workers with different disciplines also plays a role in discharge planning. Ellza y wong et al (2011) explained that the potential barriers included lack of standardized policy-driven discharge planning programs, and lack of communication and coordination among different health service providers and patients in both acute and sub-acute care settings were identified as main system issues. Improving the quality of hospital discharge was suggested, including a multidisciplinary approach with clear identified roles among healthcare professionals. Communication of health professionals' enhancement of knowledge and patient psychology (Wong et al., 2011).

\section{Lack of nurse communication in hospitals with nurses in community services}

Discussion in research Pauline Voie (2018) explained that the NICU nurses and parents were not clearly defined, and the public health nurse competence groups were not clearly defined.

\section{There is a family role in implementing discharge planning}

The role of the family cannot be denied that as a support system it is very helpful, especially when the patient is at home. The patient will feel motivated to obey the treatment in order to speed up his recovery. The role of the family as caregiver, observer, and reminder to always remind the importance of being obedient in the treatment corridor (Fitzgerald, Nurs, \& Lecturer, 2011).

\section{Pro-active treatment rooms carry out discharge planning}

Rudd Carolyne et al. (2013) in her research, found that treatment rooms that proactively carry out discharge planning will be able to reduce the length of stay and decrease costs (Collins, 2017).

Effective in communication and effective continuity

Rosemarry Watts et al (2005) implies that several factors influence the effectiveness of the implementation of the discharge including; inadequate communication, unplanned discharge, lack of time, lack of knowledge, and continuity of staff. Meanwhile, it is found that the factor that enhances effective communication is $43 \%$, and the impedance factor is continuity of staff is $38 \%$ ( $R$. Watts et al., 2005).

\section{DISCUSSION}

In this article of existing studies, an analysis factors influence effective discharge planning implementation at the hospital. From this systematic review, we try to show there are some factors involve in it. The study result implies the effectiveness implementation discharge planning was influenced by level of knowledge of a nurse, patients readiness for discharge, discharge planning that has applicability capabilities, lack of planning of discharge programs and lack of coordination of health workers, family role in implementing discharge planning, proactive treatment rooms carry out discharge planning, and, effective in communication and effective continuity. In this discussion, the author tries to categorise four major points that have a role for 
effective discharge planning implementation namely; 1.Nurse 2.Role patient and Family in discharge planning 3. Discharge planning that has applicability capabilities 4. Effective in communication and effective continuity. Those items will intercorrelate each other.

As it has been explained that discharge Planning is one of variance nursing duty agendas. This is not only too complicated but also Long term activity, starting from patients are admitted to the hospital until they are allowed to go home. It gives nurse responsibility to do discharge planning properly. There fore, They who have been trained in the method and concept of discharge planning will be more effective in implementing discharge planning than nurses who have not trained (Abdulrdha \& Mansour, 2018). and rooms that proactively carry out discharge planning will be able to reduce the length of stay and decrease costs (Collins, 2017) It explain when nurses have good knowledge, awareness, and, motivation regarding discharge planning will be done effectively. Furthermore, a skilfull nurse who applies effective discharge planning will really provide good effects on the patient and their family. They will analyse, examine, and educate the need care of the patient and their family, including the need for physical, psychological, cognitive, and, social. It will induce capacity patient readiness to do discharge planning at home (Kaya \& SainGuven, 2018) and The role of the family as a care giver, observer, and a reminder to always remind the importance of being obedient in the treatment corridor (Fitzgerald et al., 2011). Another discussion of discharge planning is about discharge planning that has less. Applicability capabilities, such kind research Carrie HK et al. (2012) states that; the ability of the discharge planning format to be implemented is very influential for effective discharge planning (Wong et al., 2011). It reflects not only how important to involve many sides nurses/ health worker to create feasible discharge planning. But also standardise policy-driven due discharge planning program. The last, crucial point for effectiveness implementation discharge planning refers to effective in communication and effective continuity. This issue become important because communication in discharge planning must touch all health professional worker/people who have discharge planning interest purposely. Communication in the discharge planning is in writing and non-writing form, there fore, it have to be be guaranteed continuity at the right hand and the right form from sender up to receiver. By applying discharge planning that has powerfull applicability is hoped Communication and continuity will be not interrupte.

Finally, Discharge planning provides interventions and can work together in care tasks ners range. The nurses must be able to elaborate co relationships to the interprofessional health worker, patient, and, family patient as support system related to applying an appropriate standardised discharge planning to patients, As the result, quality of nursing care, satisfaction and safety patient will increase also.

\section{CONCLUSION}

Based on this study, there is a consideration that discharge planning as an important part of current health services. This planning is a systematic process starting when the patients were admitted and up to allow to the left the hospital. Discharge planning must be focused on the patient's needs and problems, which includes prevention, rehabilitative and nursing care that provide patients and families understanding and information the disease and caring interventions for further treatment at home. In deep discussion, the effectiveness implementation discharge planning at hospital was influenced by some factors including; level of knowledge of a nurse, patients readiness for discharge, discharge planning that has applicability capabilities, lack of planning of discharge programs and coordination of health workers, family role in implementing discharge planning, pro-active treatment rooms carry out discharge planning, and, effective in communication and effective continuity. At this moment, the author finds to categorise four major points that have a role for effective discharge planning implementation namely; 1 . Nurse 2.Role patient and Family in discharge planning 3. Discharge planning that has applicability capabilities 4 . Effective in communication and effective continuity. Those items will intercorrelate each other. By concerning toward some factors that have been discussed before, it will guide nurses to apply an appropriate standardised discharge planning to patients, As the result, quality of nursing care, satisfaction and safety patient will increase also.

\section{REFERENCES}

Abdulrdha, \& Mansour. (2018). Effectiveness of an instructional program on nurse's knowledge and practice concerning patients discharge planning post cardiac surgery at cardiac centers and hospitals inbaghdad city. Journal of Nursing Management, 26, 707-716.

Backer, T. E., Howard, Æ. E. A., \& Moran, Æ. G. E. (2007). The Role of Effective Discharge Planning in Preventing Homelessness. Journal Primary Prevent, 28, 229-243. https://doi.org/10.1007/s10935-007-0095-7

Collins, D. (2017). Assessing the effectiveness of advanced nurse practitioners undertaking home visits in an out of hours urgent primary care service in England. Journal of Nursing Management, 25, 519-530.

Durocher, E., Gibson, B. E., \& Rappolt, S. (2016). Mediators of marginalisation in discharge planning with older adults. Cambridge University Press.

Fitzgerald, L. R., Nurs, D. T., \& Lecturer, S. (2011). Hospital discharge: recommendations for performance improvement for family carers of 


\section{H. SOEBAGIYO, ET AL.}

people with dementia. Australian Health Review, 364-370.

Kaya, S., \& SainGuven, G. (2018). Patients' readiness for discharge: Predictors and effects on unplanned readmissions, emergency department visits and death. Journal of Nursing Management.

Mohamed, S., Parker, S., \& Arbon, P. (2014). A survey of Malaysian Critical Intensive Care unit nurses ' awareness of patients ' transition experiences ( PE ) and transitional care practice ( TCP ). Intensive \& Critical Care Nursing, 30(4), 196-203. https://doi.org/10.1016/j.iccn.2013.12.006

Roberts, S., \& Moore, L. (2018). Improving discharge planning using the re-engineered discharge programme. Journal of Nursing Management.

Watts, R., Gardner, H., \& Pierson, J. (2005). Factors that enhance or impede critical care nurses ' discharge planning practices. Intensive and Critical Care Nursing, 21, 302-313. https://doi.org/10.1016/j.iccn.2005.01.005

Watts, R. J., Pierson, J., \& Gardner, H. (2005). How do critical care nurses define the discharge planning process? Intensive and Critical Care Nursing, 21,
39-46.

https://doi.org/10.1016/j.iccn.2004.07.006

Wong, E. L. Y., Yam, C. H. K., Cheung, A. W. L., Leung, M. C. M., Chan, F. W. K., \& Wong, F. Y. Y. (2011). Barriers to effective discharge planning: a qualitative study investigating the perspectives of frontline healthcare professionals. BMC Health Services Research, 11(1), 242. https://doi.org/10.1186/1472-6963-11-242

Yam, C. H. K., Wong, E. L. Y., Cheung, A. W. L., Chan, F. W. K., Wong, F. Y. Y., \& Yeoh, E. (2012). Framework and components for effective discharge planning system: a delphi methodology. BMC Health Services Research, 12(1), 1. https://doi.org/10.1186/1472-6963-12-396

Yilmaz, M. C., \& Ozsoy, S. A. (2010). Effectiveness of a discharge-planning program and home visits for meeting the physical care needs of children with cancer. Springer, 243-253. https://doi.org/10.1007/s00520-009-0650-2 